J. Lake Sci.(湖泊科学), 2009, 21(1): 117-122

http://www.jlakes.org. E-mail: jlakes@niglas.ac.cn

(C2009 by Journal of Lake Sciences

\title{
新疆乌伦古湖河鲈二十年来种群生长变化及原因
}

\author{
唐富江 ${ }^{1}$, 姜作发 ${ }^{1 * *}$, 阿达可白克・可尔江 ${ }^{2}$, 霍堂斌 ${ }^{1}$, 蔡林钢 $^{2}$ \\ (1: 中国水产科学研究院黑龙江水产研究所, 哈尔滨 150070) \\ (2: 新疆维吾尔族自治区水产科学研究所, 乌鲁木齐 830000)
}

摘 要: 新疆乌伦古湖是中国内陆主要渔业基地之一. 为了充分开发其渔业资源, 在过去的 40 余年中共引进鱼类 15 种; 乌伦 古湖土著鱼类的生态位大部分已经为外来鱼类所占据, 曾为乌伦古湖最重要的土著经济鱼类的河鲇物种濒临灭绝. 为了探讨 河鲇种群数量锐减的原因和外来鱼类对乌伦古湖土著鱼类的人侵机制, 2007-2008 年对乌伦古湖河鲇的生长状况进行了调查, 并与 1987-1989 年的调查数据进行了比较分析. 调查结果表明: 除 $1^{+}$龄组外, 乌伦古湖河鲇其它各龄组的平均体长和体重均 明显减小; 拟合 Von Bertalanffy 生长方程的各参数 $L_{\infty}=41.317 \mathrm{~cm}, W_{\infty}=15475.1 \mathrm{~g}, k=0.1649, t_{0}=-0.2626$; 求得生长特征指数 $\Phi$ =2.4493. $L_{\infty}$ 和 $\Phi$ 值明显减小, $k$ 值有所增加; 但生长式型没有改变, 生长拐点与 1987-1989 年一致, 仍为 $t_{I P}=7$. 探讨了乌伦古 湖河鲇种群生长变化的主要原因及作用机制.

关键词: 乌伦古湖; 鱼类人侵; 河鲇; 生长变化; 制约机制

\section{Perch(Perca fluviatilis Linnaeus) growth variation and inducing reasons of Lake Ulungur, Xinjiang Province in the last two decades}

\author{
TANG Fujiang ${ }^{1}$, JIANG Zuofa ${ }^{1}$, Adakbek Karjan ${ }^{2}$, HUO Tangbin ${ }^{1} \&$ CAI Lingang ${ }^{2}$ \\ (1: Heilongjiang River Fishery Research Institute of Chinese Academy of Fishery Sciences, Harbin 150070, P.R.China) \\ (2: Fishery Institute of Xinjiang Uygur Autonemous Province, Urumqi 830000, P.R.China)
}

Abstract: Lake Ulungur is one of the most important fishery ground in Chinese inland area. To exploit the potential fishery resources, 15 species of fishes were introduced in the past 40 years. By far, most of the niches to the fishes endemic in Lake Ulungur were occupied by the introduced fishes. Perch(Perca fluviatilis Linnaeus) as the most economic important fish has endangered. The age structure and growth of perch population were studied in 2007-2008, and compared with the corresponding data in 1987-1989 to analyze the reason why population size decreased sharply. Body weight and length of captured perch were both smaller than those in 1987-1989 at each age except age $1^{+}$. The growth parameters using Von Bertalantty equations were $L_{\infty}=41.317 \mathrm{~cm}, W_{\infty}=15475.1 \mathrm{~g}$, $k=0.1649, t_{0}=-0.2626$; growth performance indices were $\Phi=2.4493 . L_{\infty}$ and $\Phi$ reduced since $1987-1989$ while $k$ increased. However, the growth inflection point of body weight was the same as 1987-1989 ( $t=7)$. This investigation confirmed the remarkable effects of environment factors on perch growth and the effect mode of fish invasion on Perch(Perca fluviatilis Linnaeus) growth in Lake Ulungur were also revealed.

Keywords: Lake Ulungur; fish invasion; Perch (Perca fluviatilis Linnaeus); growth variation; stress mechanism

乌伦古湖，是新疆第二大湖，也是我国内陆主要渔业基地之一，位于准葛尔盆地北部，是乌伦古河 的尾问湖，系额尔齐斯河一支流乌伦古河在冰川期前与额尔齐斯河断裂形成 ${ }^{[1]}$, 属于额尔齐斯河水系的 附属湖泊; 位于东经 $87^{\circ} 1^{\prime}-87^{\circ} 35^{\prime}$, 北纬 $46^{\circ} 59^{\prime}-47^{\circ} 25^{\prime}$, 海拔 $468 \mathrm{~m}$; 由布伦托海和吉力湖 2 个主要水体组成.

\footnotetext{
* 国家环境保护部物种调查专项资金资助. 2008-06-16 收稿; 2008-10-13 收修改稿. 唐富江, 男, 1979 年生, 硕士, 助理研 究员; E-mail: rivery2008@163.com.

** 通讯作者; E-mail: jzffish@163.com.
} 
于 1971 年开通了 “引额济海” 渠, 将额尔齐斯河的水引人乌伦古湖; 目前布伦托海面积 $745 \mathrm{~km}^{2}$, 蓄水量 $59 \times 10^{8} \mathrm{~m}^{3}$, 平均水深 $7.9 \mathrm{~m}$; 吉力湖面积 $172 \mathrm{~km}^{2}$, 蓄水量 $15 \times 10^{8} \mathrm{~m}^{3}$, 平均水深 $8.7 \mathrm{~m}^{[2]}$. 建国以来, 我国学 者对乌伦古湖的地理和生物学进行了较为系统的调查研究 ${ }^{[1-10]}$. 乌伦古湖作为荒漠中的湖泊, 土著鱼类 区系组成简单, 仅有 7 种土著鱼类, 分别为河鲈 Perca fluviatilis Linnaeus、贝加尔雅罗鱼 Leuciscus leuciscus baicalensis (Dybowski)、丁鱥 Tinca tinca(Linnaeus)、尖鳍鮈 Gobio gobio acutipinnatus Men'schikov、西伯利亚花鲉 Cobitis taenia sibicrica Gladkov、北方条鱾 Nemachilus barbstulus toni(Dybowski)、银鲫 C. auratus gibelio (Bloch) ${ }^{[3]}$. 在 19 世纪 60-70 年代, 土著种河鲈 Perca fluviatilis Linnaeus 和贝加尔雅罗鱼 Leucicus Leucicus baicalensis (Dybowski) 为乌伦古湖的主产鱼类. 自 1965 年, 乌伦古湖开始外来鱼类的人为引进, 经过了 40 年的鱼类区系组成变迁和群落结构演替, 至 2006 年乌伦 古湖鱼类种类增加为 22 种. 外来鱼类池沼公鱼成为乌伦古湖的主产鱼类; 而曾作为乌伦古湖主产鱼类的 土著种河鲈已处于濒危状态 ${ }^{[10]}$, 为了研究河鲇种群发展受外界环境变化的制约机制, 于 2007 年 4 月至 2008 年 3 月对河鲈的生长进行了调查, 并与 1987-1989 年的调查结果进行了比较分析.

河鲇(Perca fluviatilis Linnaeus), 属鲇形目(Perciformes), 鲇科(Percidae), 鲇属(Perca ${ }^{[11]}$. 广泛分布于 比利牛斯半岛以外的全欧洲，以及黑海、里海和咸海等水系，东到科雷马河的西伯利亚地区，也称为欧亚 鲇(Eurasian perch), 在我国仅分布于新疆北部的额尔齐斯河水系, 是当地的主要经济鱼类 ${ }^{[12]}$. 我国对乌 伦古湖河鲇的年龄、生长、繁殖和食性的研究均有报道 ${ }^{[5,7-8,13-15]}$, 使得本次生长比较研究成为可能.

\section{1 材料与方法}

\section{1 样品采集}

本研究的河鲇样品采自乌伦古湖渔场各捕鱼点, 采集时间为 2007 年 4 月至 2008 年 3 月; 采集网具 为当地捕捞河鲇普遍采用的单层挂网, 网目为 $5 \mathrm{~cm} 、 6 \mathrm{~cm}$ 和 $8 \mathrm{~cm} 3$ 种规格, 网长 $40 \mathrm{~m}$, 网高 $1.5 \mathrm{~m}$; 共采集 到河鲇样品 157 尾.

\section{2 研究方法}

将所渔获河鲇鲜活个体进行体长、体重测量; 体长精确到 $0.1 \mathrm{~cm}$, 体重精确到 $1 \mathrm{~g}$. 河鲈的主鳃盖骨则 作为年龄鉴定较好的研究材料, 被国内外学者所广泛采用 ${ }^{[5,11,14]}$, 本研究亦采用主鳃盖骨作为年龄鉴定材 料, 煮沸约 3-5 min, 清洗干净, 再浸泡于酒精中 $1 \mathrm{~min}$. 借助于 MOTIC 解剖镜和投影仪, 年轮鉴别参照黄 诚 ${ }^{[13]}$ 的鉴定方法.

\section{3 数据处理}

通过统计分析软件 SPSS13.0 和 EXCEL2003 进行数据统计分析处理. 采用如下相关公式进行数据分 析:

体长与体重的相关 Keys 公式:

$$
W=a L^{b}
$$

Von Bertalanffy 生长方程:

$$
L_{t}=L_{\propto}\left[1-\mathrm{e}^{-k\left(t-t_{0}\right)}\right], W_{t}=W_{\propto}\left[1-\mathrm{e}^{-k\left(t-t_{0}\right)}\right]^{b} ;
$$

生长特征指数:

$$
\Phi=\lg k+2 \lg L_{\infty}
$$

上述公式中, $W$ 为体重 $(\mathrm{g}) ; L$ 为实测体长 $(\mathrm{cm}) ; L_{\infty}$ 为渐进体长, $W_{\infty}$ 为渐进体重, $k$ 为生长系数, $t_{0}$ 为假定的理 论生长起点年龄.

\section{2 结果}

\section{1 捕捞群体结构的变化}

在 2007-2008 年采集样品年龄由 $2^{+}-6^{+}$龄组成, 其中 $3^{+}$龄个体最多, 占总数的 $62 \% ; 6^{+}$龄个体最少, 仅 采到 3 尾(表 1). 与 1987-1989 年调查数据 ${ }^{[13]}$ 相比, 同龄组的河鲇个体体长和体重均发生了明显的变化, 除 $1^{+}$龄组外, 其他各年龄组体长、体重均明显减小(图 1). 
表 1 乌伦古湖河鲈捕捞群体结构两次调查间的差异

Tab.1 The variation of captured population structure of perch in Lake Ulungur between two investigations

\begin{tabular}{|c|c|c|c|c|c|c|}
\hline \multirow{2}{*}{ 年龄 } & \multicolumn{2}{|c|}{ 数量 } & \multicolumn{2}{|c|}{ 平均体长 $(\mathrm{cm})$} & \multicolumn{2}{|c|}{ 平均体重(g) } \\
\hline & $1987-1989^{[13]}$ & $2007-2008$ & $1987-1989$ & $2007-2008$ & 1987-1989 & $2007-2008$ \\
\hline $1^{+}$ & 690 & 38 & $10.74 \pm 1.61$ & $10.45 \pm 1.09$ & $16.5 \pm 3.53$ & $20.5 \pm 6.35$ \\
\hline $2^{+}$ & 320 & 62 & $16.02 \pm 2.92$ & $13.74 \pm 1.72$ & $72.9 \pm 29.21$ & $53.3 \pm 20.72$ \\
\hline $3^{+}$ & 180 & 27 & $21.29 \pm 2.21$ & $16.55 \pm 2.06$ & $288.5 \pm 61.88$ & $88.7 \pm 27.89$ \\
\hline $4^{+}$ & 75 & 19 & $25.56 \pm 2.48$ & $20.00 \pm 1.10$ & $405.3 \pm 53.72$ & $189.4 \pm 45.61$ \\
\hline $5^{+}$ & 30 & 11 & $29.08 \pm 3.12$ & $25.20 \pm 0.00$ & $765.9 \pm 144.3$ & $343.00 \pm 0.00$ \\
\hline $6^{+}$ & 9 & & $34.00 \pm 1.27$ & & $965.0 \pm 130.9$ & \\
\hline $7^{+}$ & 4 & & $36.25 \pm 1.09$ & & $1387.0 \pm 99.2$ & \\
\hline $8^{+}$ & 2 & & $38.55 \pm 1.31$ & & $1410.0 \pm 75.58$ & \\
\hline $9^{+}$ & 1 & & 40.00 & & 1700 & \\
\hline
\end{tabular}
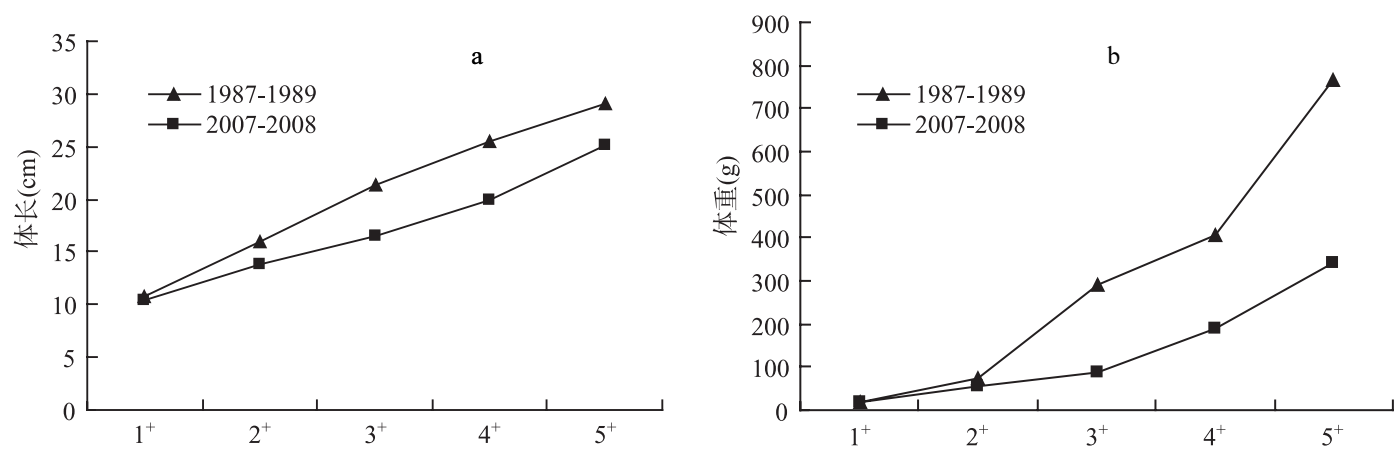

图 1 乌伦古湖河鲈各龄组体长(a)和体重变化(b)

Fig.1 Changes of perch body length(a) and body weight(b) at each age in Lake Ulungur between two investigations

\section{2 体长、体重关系}

以采集的河鲇样品体长 $(L, \mathrm{~cm})$ 和相应的体重 $(W, \mathrm{~g})$ 作散点图分析, 得河鲇体长体重关系式及曲线:

$$
W=0.0091 L^{3.293} \quad\left(r^{2}=0.9969, n=50\right)
$$

\section{3 生长方程}

以河鲇不同年龄组的平均退算体长拟合 Von Bertalanffy 生长方程, 用 $L_{t+1}$ 对 $L_{t}$ 作回归分析图, 得到典 型的 Walford 线, 可满足 V.B.G.F.的描述条件, 用最小二乘法求得河鲈的各项生长参数为: 渐进体长 $L_{\infty}$ $=41.317 \mathrm{~cm}$, 渐进体重 $W_{\infty}=15475.1 \mathrm{~g}$, 生长系数 $k=0.1649$, 生长起点年龄, $t_{0}=-0.2626$, 由各参数值得体长、 体重生长方程和曲线(图 2):

$$
\begin{gathered}
L_{t}=41.31\left[1-\mathrm{e}^{-0.1649(t+0.2626)}\right] \\
W_{t}=15475.13\left[1-\mathrm{e}^{-0.1649(t+0.2626)}\right]^{3.293}
\end{gathered}
$$

$F$ 检验结果表明，上述生长方程的回归极显著 $(P<0.01)$. 将各龄的实测体长和推算体长进行 $X^{2}$ 检验, $X^{2}=0.0390<X^{2}{ }_{0.05}=9.488, P=0.9998>0.05$, 说明差异极不显著, 与 1987-1989 年分析结果 ${ }^{[13]}$ 相同, Von.Bertalanffy 生长曲线的拟合程度可靠, Von.Bertalanffy 方程可以很好地描述当今乌伦古湖河鲈的种群 生长规律. 


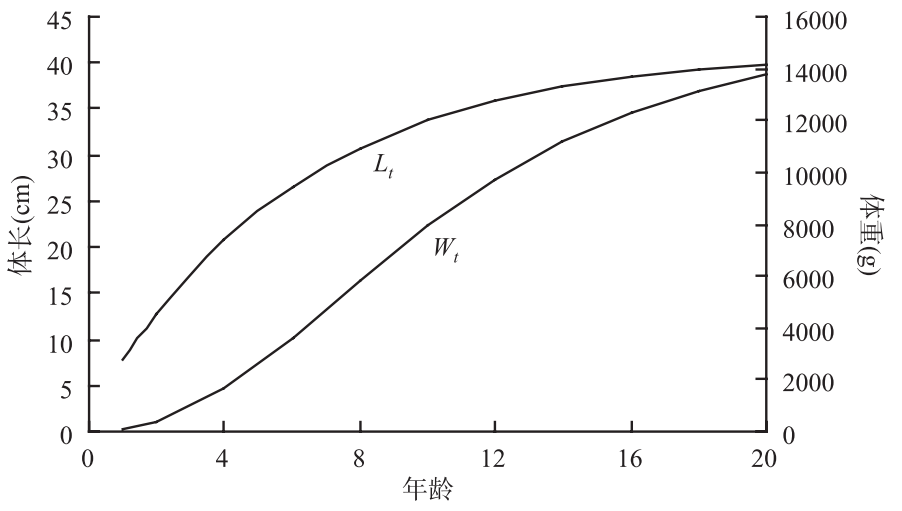

图 2 乌伦古湖河鲇体长与体重生长曲线

Fig.2 Growth curve of body length and body weight of perch in Lake Ulungur

对生长方程(2)、(3)式求二阶偏导得体长、体重生长加速度方程(4)、(5):

$$
\begin{gathered}
\mathrm{d}^{2} L / \mathrm{d} t^{2}=-1.1233 \mathrm{e}^{-0.1649(t+0.2626)} \\
\mathrm{d}^{2} W / \mathrm{d} t=1385.69 \mathrm{e}^{-0.1649(t+0.2626)}\left[1-\mathrm{e}^{-0.1649(t+0.2626)}\right]^{1.293}\left[3.1123 \mathrm{e}^{-0.1649(t+0.2626)}-1\right]
\end{gathered}
$$

当体重的生长加速度为零时的年龄为生长拐点年龄, 将相应生长参数 $b, t_{0}$ 和 $L_{\infty}$ 代入方程求得拐点年 龄 $t_{I P}=7$. 拐点体重为 $W_{i}=4738.28$; 此后河鲇的体重生长速度逐渐减慢. 拐点年龄与 1987-1989 年研究结 果 ${ }^{[13]}$ 相同, 很好地说明了河鲈的生长式型没有改变.

\section{4 河鲇种群的生长参数的变化}

将 V.B. 生长方程中的 $k$ 和 $L_{\infty}$ 代人生长特征指数方程 $\Phi=\lg 10 k+2 \lg 10 L_{\infty}$, 得到乌伦古湖河鲈生长特 征指数 $\Phi=2.4493$.

本次调查与 1987-1989 年调查拟合的生长参数表现了明显的不同; $b 、 L_{\infty} 、 k 、 t_{0}$ 和 $\Phi$ 值均出现了明显 的变化(表 2). $L_{\infty}$ 值由 $53.63 \mathrm{~cm}$ 减小到 $41.31 \mathrm{~cm}, k$ 值有所增加，与 Moreau ${ }^{[16]}$ 揭示的 $L_{\infty}$ 和 $k$ 值之间存在着负 相关相一致. $\Phi$ 值的减小很好地揭示了当前乌伦古湖河鲇种群生长状况变差的趋势.

表 2 乌伦古湖河鲈的生长参数比较

Tab.2 Growth parameters comparation of perch in Lake Ulungur

\begin{tabular}{cccccc}
\hline 时间 & $b$ & $L_{\infty}(\mathrm{cm})$ & $k$ & $t_{0}$ & $\Phi$ \\
\hline $1987-1989$ 年 ${ }^{[13]}$ & 3.1986 & 53.65 & 0.15 & -0.41 & 2.6352 \\
$2007-2008$ 年 & 3.293 & 41.31 & 0.1649 & -0.2626 & 2.4493 \\
\hline
\end{tabular}

\section{3 讨论}

\section{1 乌伦古湖外来鱼类入侵与河鲇种群变动}

经过 40 余年的鱼类引种移殖和通渠流人，乌伦古湖共引入外来鱼类 14 种和 1 个天然杂交种. 在 1965-1970 年间，额尔齐斯河的鲤 Cyprinus (Cyprinus) carpio Linnaeus、东方欧鳊 Abramis brama orientalis Berg、湖拟鲤 Rutilus rutilus lacustris (Pallas)和长江流域的草鱼 Ctenopharpharyngodon idellus(Curier et Valenciennes)相继被移人到乌伦古湖；1971 年引额济海工程开通后，随水流人白斑狗鱼 Esox lucius Linnaeus、梭鲈 Stizostedion luciperca (Linnaeus)、江鳕 Lota lata (Linnaeus)、高体雅罗鱼 Leucicus idus (Linnaeus)、哲罗鲑 Hucho taimen (pallas)、粘鲈 Acerina cernua Linnaeus 和湖拟鲤 Rutilus rutilus lacustris (Pallas) $\times$ 东方欧鳊 Abramis brama orientalis Berg 的天然杂交种; 1980 年以后引人了鲢 Hypophthalmichthts molitrix (Cuvie et Valenciennes)、鳙 Aristichthys nobilis (Richardson), 同时无意带人了麦穗鱼Pseudorasbora parva (Temminck et schlegal); 1991 年引人池沼公鱼 Hypomesus olidus Pallas ${ }^{[10]}$. 
乌伦古湖的鱼类群落结构经过一次次的变迁, 已经发生了巨大变化, 随着新种的不断引进, 乌伦古 湖的鱼类优势种也在发生着演替. 1959-1988 年间，乌伦古湖年均渔产量为 2102t, 土著鱼类河鲇和贝加 尔雅罗鱼分别占总产量的 10\%和 80\%；1989-1996 年间，乌伦古湖年均渔产量为 3237t, 外来鱼类东方欧 鳊(1965 年引人)、白斑狗鱼(1971 年流入)和湖拟鲤(1965 年引入)在此期间产量迅速上升, 到 1996 年, 分 别占年总产量的 $40 \% 、 20 \%$ 和 $10 \%$ ，土著种河鲇和贝加尔雅罗鱼各占总产量的 $1 \%$ ，由于该期间渔业总产 量高且稳定，河鲇虽然数量有所下降但仍有一定产量; 在 1997-2001 年间，乌伦古湖年均渔产量为 3067t, 外来鱼类池沼公鱼 $(1991$ 年引人)占总产量的 $40 \%$, 东方欧鳊占 $30 \%$, 白斑狗鱼占 $18 \%$, 河鲇的产量突然下 降，在捕获群体中仅剩相对高龄个体，占总产量 $0.1 \% ; 2002-2006$ 年间，年均渔产量 2716t, 池沼公鱼已经 占到了乌伦古湖鱼产量 $60 \%$, 东方欧鳊减少到总产量的 $13 \%$, 白斑狗鱼确维持较好的产量, 河鲈已经濒 危(表 3).

表 3 乌伦古湖主要鱼类产量的变动历史

Tab.3 Variation history of main economic fish product in Lake Ulungur

\begin{tabular}{cccccccc}
\hline \multirow{2}{*}{ 时间 } & \multicolumn{5}{c}{ 主产鱼类占年均产量的比重 $(\%)$} & 年均渔产量 \\
\cline { 2 - 5 } & 河鲈 & 贝加尔雅罗鱼 & 东方欧鳊 & 白斑狗鱼 & 湖拟鲤 & 池沼公鱼 & $(\mathrm{t})$ \\
\hline $1959-1988$ 年 & 10 & 80 & & & & & 2102 \\
$1989-1996$ 年 & 1 & 1 & 40 & 20 & 10 & & 3237 \\
$1997-2001$ 年 & 0.1 & 0.5 & 30 & 18 & & 40 & 3067 \\
$2002-2006$ 年 & 濒危 & 0.1 & 13 & 20 & 60 & 2716 \\
\hline
\end{tabular}

通过乌伦古湖主产鱼类的历史变迁和河鲇产量的变化表明，东方欧鳊、白斑狗鱼和湖拟鲤的移殖， 特别是池沼公鱼的引进和爆发性增殖, 是导致了土著鱼类河鲇种群数量锐减的主要原因. 河鲇是以动物 性旿料为主要食物的鱼类, 曾于 1968 年被移殖到新疆博斯腾湖, 于 1977 年爆发性增殖后达到了无法控 制的地步，导致了土著种塔里木裂腹鱼的濒危和国家一级保护动物新疆大头鱼的灭绝 ${ }^{[17]}$; 后来同样在博 斯腾湖于 1991 年引入的池沼公鱼自 1994 年始爆发性增殖后, 河鲇的产量突然下降，在捕获群体中仅剩 相对高龄个体, 补充群体消失, 目前博斯腾湖河鲈也已濒危 ${ }^{[18]}$. 因此, 池沼公鱼对河鲈的取代作用较其 它鱼类更为明显.

\section{2 鱼类生长的可塑性和抑制乌伦古湖河鲇生长的直接原因}

鱼类的生长发育与栖息环境的关系十分密切的, 在不同的水域环境中, 饵料生物、物理化学因子及 鱼类群落环境均有所差异, 鱼类生长参数往往表现出明显的差别. 其中, 食物因子和能量转换效率在决 定鱼类生长速度上起很重要的作用. 新疆赛里木湖中移殖的高白鮏和虹䲡, 由于生长环境的适宜, 适口 饵料鈎虾生物量高, 生长速度均表现出快于原产地 ${ }^{[19-20]}$; 而移殖的贝加尔雅罗鱼则由于饵料不适口和水 温低等表现出生长极其缓慢, 在原产地乌伦古湖中 4 年能达到 $20 \mathrm{~cm}$, 在赛里木湖中则需要 8 年; 而移殖 到博斯腾湖中的贝加尔雅罗鱼达到 $20 \mathrm{~cm}$ 也仅需 4 年 ${ }^{[21]}$. 陈毅峰和李秀启等 ${ }^{[22]}$ 报道了抚仙湖外来黄滪鱼 生长趋缓, 但由于秀丽白虾等适口饵料丰度的增加趋势, 黄滪鱼表现出很好的生长潜力.

鉴于 “引河济海”工程开通于 1971 年, 而本文比较的年份(1988-1996 年, 1997-2001 年, 2002-2006 年)均在引水后 16 年之后, 因此水化学变化不是导致河鲇生长变化的主要因素, 并且目前的各项水化学 指标完全符合渔业水质标准 ${ }^{[22]}$. 相关调查表明 2007 年乌伦古湖覀料生物的数量和生物量较 1987 年均大 为减少, 河鲇的喜好饵料摇蚊幼虫的生物量仅为 1987 年的 $1 / 10^{[23]}$; 河鲇的食性由原来的以摇蚊幼虫为主 转变为以池沼公鱼为主 ${ }^{[24]}$; 因此, 认为乌伦古湖的适口饵料缺乏导致了河鲇营养状况不佳, 是影响河鲇 生长速度的重要原因.

\section{3 乌伦古湖环境因子的变化导致河鲇生长变化的规律}

本次研究发现, 乌伦古湖河鲇种群除 $1^{+}$龄以外的各龄组体长、体重均变小, 各生长参数也说明了生 长状况变差; 但生长式型没有变, 体重加速度拐点和生长拐点年龄与 1987-1989 年完全一致, 说明了乌 伦古湖河鲇生存环境的变化没有改变河鲇生长的本质特性和规律，只是制约了生长的速度，这也是环境 
因子的作用不改变鱼类本质生长特性的一个例证.

\section{4 参考文献}

[1] 严尚钦, 夏训诚. 新疆额尔齐斯河与乌伦古河流域地貌发育. 地理学报, 1962, 28(4): 257-272.

[2] 李立人, 王雪冬. 乌伦古湖水质现状及污染防治对策. 干旱环境监测, 2003, 17(2): 103-106.

[3] 李思忠, 戴定远, 马桂珍等. 新疆北部鱼类的调查研究. 动物学报, 1966, 18(1): 41-56.

[4] 马桂珍. 乌伦古湖的生态平衡及其与渔业关系的探讨. 干旱区研究, 1986, (1): 39-43.

[5] 任慕莲. 新疆吉力湖的渔业. 哈尔滨: 黑龙江科学技术出版社, 1990.

[6] 袁方策. 阿勒泰地区科学考察论丛. 北京: 科学出版社, 1991.

[7] 黄＼cjkstart诚, 孟文新, 陈建秀等. 河鲇食性分析及其摄食生态策略. 水产学报, 1998, 22(4): 309-313.

[8] 黄 诚, 葛家春, 刘仁华. 新疆河鲇(Perca fluviatilis Linnaeus)繁殖生态学参数解析. 水产养殖, 1996, (3): 16-18.

[9] 王宪栕, 王洪道, 张开翔等. 新疆乌伦古湖自然条件及其渔业生物学基础的初步研究. 海洋湖沼通报, 1981, (4): 18-27.

[10] 阿达可白克 - 可尔江, 苏德学, 杨 燕等. 乌伦古湖鱼类资源现状及保护与开发对策. 上海水产大学学报, 2006, 15(3): 308-314.

[11] 尼科里斯基 $\Gamma \mathrm{B}$ 主编. 分门鱼类学. 北京: 高等教育出版社, 1958.

[12] 李思忠. 中国淡水鱼类的分布区划. 北京: 科学出版社, 1981.

[13] 黄 诚. 新疆乌伦古湖河鲇(Perca fluviatilis Linnaeus)种群的生长模型及生态参数的研究. 南京大学学报(自然科学版), 1993, 29: 271-277.

[14] 马桂珍. 乌伦古湖河鲇(Perca fluviatilis Linnaeus)食性的研究. 干旱区研究, 1986, (2): 21-26.

[15] 阿达可白克 -可尔江, 苏德学, 海沙尔等. 乌伦古湖河鲇(Perca fluviatilis Linnaeus)生物学及开发利用对策. 新疆渔业科技, 2003, (3): 12-16.

[16] Moreau JK. Anadromous salmonid enhancement by boulder placement in Hurdygurdy Creek, California. In: Hassler T ed. Proceedings: Pacific Northwest Stream Habitat Management Workshop, 1984: 97-116.

[17] 李振宇, 解 炎. 中国外来人侵种. 北京: 中国林业出版社, 2002.

[18] 郭 炎. 博斯腾湖鱼类资源及渔业. 乌鲁木齐: 新疆科学技术出版社, 2005: 145-150.

[19] 郭炎, 张北平, 张人铭. 赛里木湖高白鲭(Coregonus peled Gmelin)引种移殖效应评价. 水利渔业, 2003, 23(3): 30-32.

[20] 郭炎, 蔡林钢, 马燕武. 虹䲡(Salmo gaidnerii Richardson)在赛里木湖生长发育的初步研究. 水产学杂志, 2007, 20(2): $1-6$.

[21] 郭 炎, 吐尔逊, 蔡林钢等. 赛里木湖贝加尔雅罗鱼(Leuciscus baicalensis )生长研究. 新疆大学学报(自然科学版), 2003, 20(3): 272-276.

[22] 李秀启, 陈毅峰, 李 枋. 抚仙湖外来黄滪鱼种群的年龄和生长特征. 动物学报, 2006, 52(2): 263-271.

[23] 唐富江. 新疆乌伦古湖外来鱼类对河鲇人侵机制的研究[学位论文]. 重庆: 西南大学, 2008.

[24] 唐富江, 姜作发, 蔡林钢等. 新疆乌伦古湖河鲇(Perca fluviatilis Linnaeus)食性的变化. 水产学杂志, 2008, 21(1): 55-58. 